\title{
EL CASO CRIMINAL DEL INDÍGENA FRANCISCO "PAMPA" ECONOMI: ALEGATOS Y ACTUACIONES DE LA JUSTICIA PROVINCIAL
}

(BUENOS AIRES, 1823)

\section{O PROCESSO CRIMINAL DO INDÍGENA FRANCISCO "PAMPA" ECONOMI: ALEGAÇÕES E ATUAÇÕES DA JUSTIÇA PROVINCIAL}

(BUENOS AIRES, 1823)

\section{THE CRIMINAL TRIAL OF INDIAN FRANCISCO "PAMPA" ECONOMI: ALLEGATIONS AND ACTIONS TAKEN BY THE PROVINCIAL COURT \\ (BUENOS AIRES, 1823)}

\section{LE PROCÈS PÉNAL DE L'INDIGÈNE FRANCISCO "PAMPA" ECONOMI : ALLÉGATIONS ET PROCÉDURES DE LA JUSTICE PROVINCIALE \\ (BUENOS AIRES, 1823)}

DOI: $10.5533 / 1984-2503-20124306$

Ángela Calabrese Bonzon ${ }^{1}$

\section{RESUMEN}

A partir de una fuente inédita consistente en una causa criminal sumamente rica en cuanto a la concepción que tenía la justicia respecto a la aplicación de la ley bonaerense, en los asuntos de los indígenas y al posicionamiento jurídico de estos actores sociales en el universo urbano de Buenos Aires durante la fase independiente temprana, este trabajo propone analizar tales cuestiones. Dichos aspectos -sobre los cuales escasamente se ha profundizado en la historiografía argentina para aquel período- se vislumbran en el contexto de un fructífero intercambio de alegatos entre el Agente Fiscal del Crimen y el Juez de Primera Instancia, por un lado y el Protector General de Pobres en representación del indígena acusado, por el otro, poniéndose en juego visiones

\footnotetext{
${ }^{1}$ Licenciada en Antropología por la Universidad Nacional de La Plata (República Argentina). Maestranda en Ciencias Sociales por la Facultad de Humanidades y Ciencias de la Educación, Universidad Nacional de La Plata. E-mail personal: a 2009@speedy.com.ar
} 
encontradas -más que congruentes- respecto al derecho natural y positivo de los hombres y a la pertinencia de aplicar el Derecho del blanco para juzgar a un indígena responsable de un delito cometido en la jurisdicción de Buenos Aires. Así, el examen del caso permite plantear la existencia de igualdad jurídica (aunque no social) para los habitantes indígenas en el marco espacio-temporal abordado, percibiendo cómo fue el accionar de la ley vigente en Buenos Aires y la modalidad de procedimiento adoptada por la institución jurídica ante los asuntos de este sector social.

Palavras-chave: Buenos Aires, derecho, indígena, periodo inicial de la independencia.

\section{RESUMO}

A partir de uma fonte inédita que consiste em um processo criminal extremamente rico, este artigo se propõe a analisar algumas questões quanto a concepção da justiça a respeito da aplicação da lei em Buenos Aires, aos assuntos indígenas e ao posicionamento jurídico dos atores sociais no universo urbano da cidade na fase inicial da independência. Estes aspectos, sobre os quais a historiografia argentina pouco se aprofundou neste período, são vislumbradas no contexto de uma frutífera troca de alegações entre o Agente Fiscal do Crime e do Juiz de Primeira Instância, por um lado, e o Protetor Geral dos Pobres na representação do índio acusado, por outro lado, mostrando visões opostas sobre o direito natural e positivo dos homens e a pertinência de se aplicar o direito do branco para um índio responsável por um crime cometido dentro da jurisdição de Buenos Aires. Assim, a análise do caso permite sugerir a existência de igualdade jurídica (embora não social) para os habitantes indígenas no contexto espaçotemporal abordado, percebendo como se deu o acionamento da lei vigente em Buenos Aires e a forma de procedimento adotada pela instituição jurídica diante deste setor social. Palavras-chave: Buenos Aires, direito, indígena, período inicial de independência.

\section{ABSTRACT}

Based on an unpublished source in the form of an extremely rich criminal trial, this article aims to analyse several questions regarding the conception of justice in the application of the law in Buenos Aires, indigenous affairs and the legal positioning of social actors in the urban universe of the city in the initial stages of its independence. These features, into which Argentine historiography barely delved in this period, are examined in the context of a revealing exchange of allegations between the Public Prosecutor and the Lower Court Judge on one hand, and the General Protector of the Poor representing the accused 
Indian, on the other hand. The exchange demonstrates opposing views on natural and positive law and the relevance of applying white men's laws to an Indian responsible for a crime committed within the jurisdiction of Buenos Aires. An analysis of the case thus serves to suggest the existence of legal (although not social) equality for indigenous inhabitants in Argentina at the time in question, suggesting how the relevant law in Buenos Aires was applied and the way the procedure was adopted by the legal institution in its treatment of this social sector.

Key words: Buenos Aires, law, Indian, initial period of independence.

\section{RÉSUMÉ}

Sur la base d'une source inédite consistant en un procès pénal extrêmement fourni, cet article propose d'analyser divers aspects liés à la conception de la justice dans l'application de la loi à Buenos Aires, aux questions indigènes et aux positions juridiques des acteurs sociaux de l'univers urbain de la ville aux premiers temps de l'indépendance. Ces aspects sur lesquels l'historiographie argentine s'est peu penchée sont envisagés dans le contexte d'un échange fructueux d'allégations entre le Procureur général et le Juge de première instance d'un côté, et entre celui-là et le Protecteur général des pauvres qui défendait l'Amérindien accusé, de l'autre, mettant en lumière des visions opposées quant au droit naturel et positif des hommes et à la pertinence d'appliquer le droit du Blanc à un Amérindien accusé d'un crime commis dans la juridiction de Buenos Aires. Cet analyse de cas permet ainsi de suggérer l'existence d'une égalité juridique (mais non sociale) en faveur des populations indigènes dans le contexte spatiotemporel en question, et de mieux comprendre l'application de la loi en vigueur à Buenos Aires et les procédures adoptées par l'institution juridique à l'égard de ce groupe social.

Mots-clés: Buenos Aires, droit, indigène, premiers temps de l'indépendance.

\section{I- Introducción}

La justicia, el derecho, la legislación y el delito se han convertido en uno de los tópicos más dinámicos de las Ciencias Sociales, tanto en Europa como en América Latina y abordados desde una perspectiva plural, se suma la mirada histórica que los enfoca 
desde la etapa colonial ${ }^{2}$. Tal como afirman Ricardo Salvatore y Carlos Aguirre $^{3}$, en las últimas décadas, la ley y los fenómenos legales se han transformado en el centro de los estudios históricos de las sociedades latinoamericanas, dando lugar a un fascinante campo de análisis. Este ámbito, resultante de la convergencia de múltiples subdisciplinas, esfuerzos y perspectivas, promete arrojar luz sobre numerosas cuestiones que responden a diversos intereses historiográficos expresados en los últimos años: las dinámicas del cambio social y cultural, la formación de las culturas legales, la interrelación entre Occidente y los sistemas legales indígenas, por mencionar sólo algunas. Precisamente, nuestro trabajo es tributario de estos avances y pretende contribuir a la comprensión del principio de la igualdad ante la ley en relación al indígena, en Buenos Aires durante los primeros años de vida independiente, cuando aspectos tales como los derechos, las garantías individuales, la formación de la nación, entre otros, conformaban parte de la agenda de discusiones políticas surgidas a partir de la Revolución de 1810.

El presente artículo presenta un estudio de caso que, en el marco de una causa judicial inédita e infrecuente en su clase entre los expedientes del Juzgado del Crimen de la época, busca demostrar la existencia de un trato de igualdad jurídica -y de equiparación civil con los demás habitantes del Estado- hacia un indígena que había cometido un delito en el seno de la jurisdicción provincial. En general, diversos asuntos de los indios ${ }^{4}$ fueron administrados por la justicia ordinaria de la campaña y la ciudad de Buenos Aires, dando lugar a procesos criminales, civiles y correccionales. De hecho, desde la Conquista ya funcionaba una normativa que regía para la República de Indios y en las fuentes los indígenas solían ser considerados como verdaderas "Naciones" durante el período hispano e independiente temprano. Por ello, para la resolución de conflictos, podía buscarse una conciliación entre dos sistemas diferentes de aplicación de la justicia: el sistema propio de los indígenas y aquel perteneciente a la administración de la justicia bonaerense, modalidad ésta comúnmente adoptada en la campaña. Consecuentemente, se conoce cómo operaba la justicia pero la figura jurídica del indígena, durante el período de la Colonia y posteriormente, republicano, es bastante confusa.

\footnotetext{
${ }^{2}$ Para más detalles, véase Gayol, Sandra y Kessler, Gabriel (Comp.) (2002). Violencias, delitos y justicias en la Argentina, Buenos Aires: Ediciones Manantial.

${ }^{3}$ Salvatore, Ricardo; Aguirre, Carlos (2001). "Introduction". In Salvatore, Ricardo; Aguirre, Carlos; Joseph, Gilbert M. (Orgs) (2001). Crime and punishment in Latin America. Law and society since late colonial times, London: Duke University Press, p. 1-25.

${ }^{4}$ Cabe destacar que por asuntos indígenas se quiere significar tanto los delitos cometidos por los indios (cuya situación jurídica resultaba ser la de procesado e imputado) y los delitos perpetrados contra los indios, como así también los pleitos con y entre los indios. Los mismos, podían aparecer en los últimos casos, en calidad de testigos, denunciantes, víctimas, sospechosos.
} 
En tal estado de cosas, para el fin propuesto, analizamos cómo procedieron las autoridades y qué discurso legitimó el accionar de los actores jurídicos intervinientes en la administración de este asunto. Los mismos, presentaron diferentes alegatos e interpretaciones referidos a los derechos naturales y positivos de los hombres y a la pertinencia o no de aplicar y juzgar al indígena mediante el régimen legal de Buenos Aires, dando lugar a un interesante debate plasmado en el expediente. El caso inició en diciembre de 1823, cuando la justicia criolla intervino para dirimir un homicidio perpetrado por Francisco Economi en la persona de Queuna, ambos indios pampas de las tolderías y temporalmente residentes en la ciudad porteña donde trabajaban -junto a un total de veintiocho indios- en el obraje de los hornos de la catedral. Este hecho dio origen a una interesante causa criminal seguida de oficio contra Economi y que exhibía un proceso judicial completo y minucioso, en el que la institución encargada de aplicar la ley, prestó atención y demostró real interés en el hecho, con su consecuente resolución y penalización. Por supuesto, no se intenta generar una respuesta acabada a través del estudio de una única causa, ya que lo ideal sería contar con otros casos similares para comparar, pero considero que la riqueza del argumento legal de este documento, permite percibir la concepción de aquella justicia en relación a las cuestiones planteadas.

\section{II- El proceso de construcción del caso criminal del indio Francisco "Pampa" Economi}

La organización judicial de la Colonia a comienzos del siglo XIX, describía una justicia consistente en un sistema de sola diferenciación de funciones y no de poderes, que se desarrollaba en tres instancias diferentes: por un lado, los encargados de administrar la justicia en primera instancia fueron los Alcaldes Ordinarios (de primero y segundo voto). Éstos eran funcionarios capitulares anualmente designados por los miembros del Cabildo, que actuaban como jueces legos; tenían a su cargo todas las causas civiles y criminales de la ciudad porteña, además de revisar las instruidas por los Alcaldes de la Santa Hermandad en el ámbito rural. Simultáneamente, el GobernadorIntendente ${ }^{5}$ ejercía la justicia ordinaria de segunda instancia en lo civil y criminal, asistido por un Teniente Letrado que intervenía en la administración de la justicia siendo el verdadero juez de alzada. Ambos funcionarios estaban subordinados judicialmente a la

\footnotetext{
${ }^{5}$ Funcionario que tenía todas las facultades de gobierno y administración de sus provincias, y estaban bajo la dirección del Virrey. Presidían los Cabildos. Eran nombrados por el Rey al igual que su Teniente Letrado.
} 
Real Audiencia -competente en la tercera instancia judicial- y en lo administrativo al Virrey.

La normativa vigente seguía la tradición legal de Castilla y la Séptima Partida era el principal texto jurídico utilizado para la resolución de los casos penales. Posteriormente a 1810, en un contexto de gran ebullición política, social y económica, emergió un nuevo orden jurídico con continuidades de la legislación colonial al tiempo que experimentaba tanto modificaciones mediante nuevos decretos, garantías, reglamentos provisionales y aplicaciones de procedimientos novedosos en materia penal, como también cambios institucionales. Por ello, el período independiente estuvo caracterizado por una gran inestabilidad jurídica debida al carácter provisional de toda la legislación del momento ${ }^{6}$. Como parte de estas transformaciones, la Real Audiencia -que funcionó desde el año 1785 y consistió en el más alto tribunal de justicia en el Virreinato del Río de la Plataquedó sustituída por la Cámara de Apelaciones (Tribunal Superior de Justicia) en 1811. Unos años después, mediante la ley del 24 de diciembre de 1821 se abolieron los cabildos, disponiéndose que la administración de la justicia ordinaria estuviera ejercida por cinco jueces de primera instancia letrados (dos en la ciudad y tres en la campaña) en reemplazo de los alcaldes aunque con sus mismas atribuciones ${ }^{7}$, quedando establecida una justicia de primera instancia letrada, descentralizada, rentada y permanente. De la misma manera, en el ámbito rural, los Alcaldes de la Santa Hermandad fueron reemplazados por los jueces de paz, a lo cual se sumó la creación del cargo de comisarios de policía.

Todos estos cambios y reestructuraciones en materia jurídica, acarrearon una reforma sustancial en la organización de la justicia, siendo en este renovado contexto donde se desarrolló la causa criminal a la que diera lugar el delito del indígena pampeano que aquí nos ocupa. Así, el caso estuvo atendido en su totalidad por las autoridades competentes del sistema de seguridad y judicial de Buenos Aires -el jefe de policía, el juez de primera instancia, el agente fiscal, el escribano- y basado en la prisión y el juzgamiento del acusado conjuntamente con la averiguación de datos mediante testigos interrogados acorde al derecho vigente y bajo declaración jurada. El único aspecto "familiarizado" con lo indígena en el proceder judicial, residió en la modalidad del juramento efectuado a los

\footnotetext{
${ }^{6}$ Para mayores detalles véase el texto de Barreneche, Osvaldo (2001). Dentro de la ley, Todo. La justicia criminal de Buenos Aires en la etapa formativa del sistema penal moderno de la Argentina, La Plata: Al Margen.

${ }^{7}$ Las bases de estas reformas estaban contenidas en el proyecto de ley redactado por la Cámara de Justicia para el establecimiento de las magistraturas que debían haber en la provincia de Buenos Aires, a pedido del gobernador Martín Rodríguez (1820-1824).
} 
indios del obraje en sus declaratorias, cuando el Juez los hizo jurar bajo la promesa de que dirían la verdad en lo que se les preguntara y según lo que crean como lo más sagrado en la "Religión Natural" a la que confesaron pertenecer.

Sin embargo, recibieron una explicación adicional del Juez sobre la obligación de no faltar a la verdad en sus declaraciones y de los cargos que pesarían sobre ellos en caso contrario. No obstante, no hemos observado este tipo de aclaraciones hacia los habitantes indígenas no procedentes de tolderías sino insertos en la sociedad hispanocriolla, al momento de ser indagados o bien interrogados. Estos últimos juraban según lo normativizado por la ley de Buenos Aires, ya que en los expedientes figura en forma generalizada que "(...) el Juez le recibió juramento que lo hizo según Derecho, bajo cuya gravedad prometió decir verdad de lo que supiere y le fuese preguntado (...),8 (el énfasis me pertenece).

Asimismo aquellas prácticas penales se combinaron con otras también propias del sistema judicial porteño: la búsqueda de evidencia material directa, ya que desde inicios del proceso, se manejó como prueba contundente de la culpabilidad de Francisco Economi, un cuchillo (del cual existe un croquis en el expediente) presentado y depositado en manos de las autoridades por parte de un testigo, el indio lenguaráz Antonio Toledo. Otra práctica fue el ordenamiento de la pericia del cuerpo de la víctima, adjuntándose el informe del médico del Departamento General de Policía, quién se apersonó en el obraje realizando el reconocimiento del cuerpo y expidió un certificado donde daba cuenta de la clase de herida efectuada, con una descripción anatómica de la misma. Por su parte, otro testigo de la causa, el Capatáz del Obraje, Ramón Gaona (procedente del extinguido Hospicio de Regulares Mercenarios) notificó por escrito haber sepultado, tras el peritaje médico, al indio Queuna en los fondos de una quinta inmediata perteneciente a dicho hospicio.

Efectivamente, los procedimientos de recolección de evidencias, constituían una etapa importante del proceso de construcción del caso criminal, al tiempo que los testimonios recibían un valor considerable e impactaban en la sentencia ${ }^{9}$. En el presente juicio, la mayoría de los testigos fueron indígenas peones del obraje, compañeros de Economi y Queuna; entre ellos se encontraban Luciano Guenchin apodado "el Muchacho"

\footnotetext{
${ }^{8}$ AHPBA. Juzgado del Crimen. 1810:4-2-33-6;1810:34-2-33-24;1812:34-2-34-20;1812:34-2-34-76;1814:342-35-75;1818:34-2-37-1;1818:34-2-37-2;1818:34-2-37-22;1818:34-2-37-52;1818:34-2-37-56; 1821:34-2-413;1822:34-2-43-24;1824:34-3-53-114;1825:34-3-58-8;1825:34-3-61-9; 1825: 34-3-62-7;1826: 34-4-68106;1827: 34-4-74-69; 1828: 34-4-81-32; 1834: 41-1-111.

${ }^{9}$ Barrebeche, O. (2001). Op. cit.
} 
y único testigo presencial de la pelea desencadenante del homicidio, junto a Victorino Gomez y Gerónimo Benites, ambos conocedores de un modo u otro de ciertos datos vinculados al crimen. Además, atestiguaron el capatáz del obraje y un pulpero. En principio, algunos fueron indagados en dos instancias distintas: primero, comparecieron ante el Comisario y sus testimonios conformaron parte del sumario levantado por la policía; posteriormente, declararon frente al Juez de Primera Instancia, el Dr. Don Roque Saenz Peña, reafirmándose en sus relatos. Esta actuación se vinculaba al hecho de que la modalidad con la que se administraba la justicia criminal, conllevaba la característica de que

el poder y la autonomía de las autoridades policiales habían crecido a partir de la década de 1810 porque estuvieron directamente vinculados a la adaptación de procedimientos legales coloniales como medidas de control social en una época de inestabilidad política. Así, las circunstancias históricas consolidaron un nicho de poder institucional (funciones judiciales absorbidas por autoridades policíacas) que permitió a la policía monopolizar las fases iniciales de todos los procesos criminales antes de que éstos llegaran a manos del juez ${ }^{10}$.

Por ello, se presentaba un alegato inicial elaborado por el comisario, con una descripción de la conducta delictiva bajo la cual las autoridades judiciales analizaban posteriormente el caso. Era común el proceso de ratificación a través del cual todos los intervinientes en el caso judicial debían presentarse ante el juez para confirmar o cambiar lo que testimoniaron frente a la policía.

Entonces presentada la defensa al juez, la misma permaneció a prueba por doce días, tiempo durante el cual se ratificaron los testigos del sumario. Es decir, durante este lapso, cada testigo se reafirmó en su declaratoria original y como algunos de ellos, particularmente Benites, Gomes y Toledo, no pudieron ser localizados de inmediato para tal fin, se ordenó rastrear sus paraderos. De este modo, sólo localizaron a Toledo, en tanto la búsqueda de los otros dos, no resultó fructífera. Consecuentemente, la justicia apeló a la alternativa de remitirse a sujetos que pudieran acreditar la idoneidad de los testigos ausentes, por conocerlos y haberlos tratado personalmente. Así, comparecieron el vecino Don Dionisio Robledo y un antiguo capatáz del obraje, Don José Agustín Astorga, quienes compartieron opiniones idénticas acerca de la buena reputación de aquellos indígenas. Ambos aseguraron que Benites y Gomes eran "hombres de bien y virtud", cuyas declaraciones debían merecer "fe y crédito en juicio y verdad", con el agregado de que el antiguo capataz del obraje, señaló que nunca había escuchado hablar

\footnotetext{
${ }^{10}$ Barrebeche, O. (2001). Op. cit., p. 18-19.
} 
mal o en contra de ellos.

Finalmente, vale destacar que los testigos tuvieron la particularidad de ser contestes: declararon de una misma manera sobre el hecho juzgado. A saber, el indio Antonio Toledo habría sido uno de los principales testigos no presenciales del caso, del momento que estando durmiendo, lo despertó el acusado entregándole personalmente el cuchillo con el que había herido a Queuna, confesándole su culpabilidad como autor material aunque callando los motivos que lo condujeron a cometer el homicidio. Según declaró Toledo, el agresor y la víctima estuvieron bebiendo aguardiente en demasía durante la noche del crimen y se hallaban sumamente ebrios, dato en el que coincidieron los testigos Benites y Gómez. A este último, Economi también confesó su homicidio asegurándole que lo había hecho por estar ebrio.

Por su parte, el pulpero Don Gabriel Carrasco -cuya pulpería se ubicaba en frente al obraje- aseguró que en la madrugada del día del crimen, el indio Economi golpeó las puertas de su negocio para comprar "un cuarto de aguardiente", en actitud amenazante y advirtiéndole que acababa de matar a un compañero suyo. La declaración de Carrasco resultó categórica porque no sólo reforzó las argumentaciones de los indios, vinculadas a la ebriedad del agresor ( $\mathrm{y}$ al hecho mismo de que el propio acusado delataba su delito) sino además reconoció el cuchillo como perteneciente al indio Economi, afirmando que se lo había visto portar repetidas veces. Otro testigo, Luciano Guenchin "el Muchacho", también identificó este cuchillo como el arma del imputado. La coincidencia entre los distintos testimonios que obraban en el expediente, quedaba plenamente evidenciada. Los mismos, fueron determinantes y tuvieron credibilidad y suficiente peso para la justicia bonaerense. De este modo, no resultó difícil la comprobación del autor penalmente responsable del delito de homicidio, debido a las evidencias presentadas y a las propias palabras del acusado totalmente confeso de su culpa y declarando su crimen en los términos expuestos a continuación.

\section{II.a- La indagatoria al imputado.}

Economi compareció por vez primera ante el Juez, con intermediación de un intérprete ya que no hablaba castellano; por su parte, el traductor fue comprometido bajo juramento, a preguntar al acusado absolutamente todo lo que ordenara la autoridad competente. En estas condiciones, se llevó a cabo una indagatoria sencilla y breve, a través de la cual el imputado respondió a unas pocas preguntas relativas a sus datos de filiación y al motivo de su prisión. Así, presentándose como Francisco "Pampa" Economi, 
declaró ser casado, mayor de 50 años de edad, natural del Arroyo de Chapaleufú, de oficio hacedor "de riendas y plumero" y de religión natural. Posteriormente, ante la pregunta acerca de si conocía el motivo de su detención, manifestó haber sido apresado a causa de una pelea sostenida con el indio Queuna. En tal sentido y respecto a cuáles habían sido los causales del pleito, expresó que la víctima provocó la situación argumento que también manejó el abogado defensor en sus primeros alegatos-, cuando el indio apodado "el Muchacho" (cuyo nombre real desconocía) robó un trozo de carne asada a Queuna; éste se disgustó violentamente y como aquel no quiso pelear, entonces el declarante intervino en defensa del joven hiriendo de muerte a Queuna con el cuchillo. Sin embargo, su versión de los hechos no coincidió con el relato de "el Muchacho". Por el contrario, este último indicó que estando jugando con su compañero Queuna lo cual denotaba una relación pacífica entre ambos. Economi, en estado de ebriedad, súbitamente hirió a Queuna con una puñalada, posiblemente a causa de que la víctima impidió a su agresor cortarse un trozo de carne de un asado. Por ello, el testigo "(...) cree que este fuese el resentimiento que trató de vengar como malo que es, conocido por tal entre todos sus compañeros (...),11

Dada la evidente oposición entre ambas declaraciones sobre los verdaderos móviles del crimen, el acusado fue sometido a una segunda indagatoria en la que se aplicó una metodología de interrogación basada en la reconvención, es decir, el juez resaltó al declarante las contradicciones de su relato porque del sumario resultó ser él -y no "el Muchacho"- quién intentó robar carne asada a Queuna y en consecuencia, el único con el que la víctima discutió. Economi se defendió asegurando no poder dar razón exacta de las circunstancias previas al hecho ni de la muerte perpetrada, porque se hallaba completamente ebrio al momento del crimen.

Sin embargo, en virtud de lo declarado por "el Muchacho", si bien Economi había estado bebiendo, su estado alcohólico no habría sido de tal magnitud al grado de perder la consciencia de sus actos, ya que pudo salir para comprar aguardiente a la pulpería y al regresar quedó custodiado por sus compañeros de trabajo a fin de evitar su fuga. En este punto, se debilitaban las afirmaciones del imputado acerca de su "inconsciencia" debida al aguardiente, no sólo por las afirmaciones de aquel testigo sino además por aquellas totalmente coincidentes de Toledo, Gomez y el pulpero, a quienes el agresor había confesado con lucidéz haber matado a un indio.

\footnotetext{
11 "Criminal contra el Indio Pampa F. Economi, por haver asesinado al de la misma clase Queuna". AHPBA. Juzgado del Crimen. 1823: 34-3-48-13.
} 
Al mismo tiempo, cuando la justicia preguntó a Economi si sabía que obró mal hiriendo a Queuna y causándole la muerte, el declarante manifestó “(...) que ignoraba fuese malo y también hubiese castigo entre los cristianos (...),12 y preguntado si en su pago se castigaba el homicidio, respondió que no y que cuando se cometía una acción de esta clase "(...) el agresor no tenía otra cosa que aser más que avisar al Casique, siendo la costumbre que si el agresor no tiene bienes con que indegnizar a los parientes ofendidos, éstos se matan en guerra con los del homicida (...)"13. Evidentemente, estas argumentaciones reflejaban parte del substrato ideológico existente en la comunidad de Economi, acercándonos a los procedimientos propios de las prácticas de la sociedad indígena, entre los cuales destacaba la aplicación del sistema de compensaciones.

La declaración indagatoria del imputado (confesión del reo) y la metodología de interrogación empleada (reconvenciones) incidieron en la graduación de la pena que eventualmente se aplicó, manera que:

(...) El Agente Fiscal del Crimen evaluando la vista que se le confiere en esta causa criminal seguida de oficio contra el Indio Fran ${ }^{c 0}$. Economi por la muerte que causó al de su misma clase llamado Queuna, acusandolo en forma dice -que del sumario aparece el expresado Economi converto y confeso del crimen que se le acusa. La herida según el certificado del facultativo fue de necesidad mortal y no hubo cosa notable $q^{e}$ precediese, o sirviese de pretexto siquiera para hacer menos horroroso este acto. Por todo ello pues, y atendiendo al estado de embriaguez en $q^{e}$ todos los testigos dicen $q^{e}$ estaba, y demas que le favorece, el Agente Fiscal concluye pidiendo se sirva de condenar al referido Fran ${ }^{c o}$. Economi a la pena de cinco años de presidio, a ración y sin sueldo con destino a las obras públicas $(\ldots)^{14}$.

Desde la perspectiva del Agente Fiscal, el delito estaba claramente comprobado, no existía justificativo alguno para un homicidio de esas características y el estado alcoholizado del agresor había funcionado como un agravante: más que excusable fue penable del momento que el Agente Fiscal establecía "y demás que le favorece", significando que la pena solicitada también castigaba a la ebriedad.

Comunicado el acusado de aquel decreto del Agente Fiscal, se le concedió el derecho de defensa en virtud del cual, pudo solicitar un Protector General de Pobres en representación suya. De esta manera, fue designado como tal Dalmacio Velez quién elevó ante las autoridades una defensa escrita donde peticionaba la absolución de Economi por considerar que un indígena de las tolderías, no debía ser juzgado según el Derecho vigente en Buenos Aires, sino que su acto criminal debía ser competencia

\footnotetext{
12 Ibidem.

${ }^{13}$ lbidem.

${ }^{14}$ AHPBA. Juzgado del Crimen. 34-3-48-13.
} 
exclusiva del sistema judicial indígena. Pero el juzgado no concedió este pedido y procesó a Economi como a cualquier otro habitante de su jurisdicción. En realidad, el único logro de la defensa consistió en que se rebajaran dos años de prisión respecto de la pena originalmente solicitada. Ahora bien, con independencia de esta resolución final, veamos en qué consistió la defensa del Protector General de Pobres y cuáles fueron sus argumentos legales.

\section{III- Entre derechos, leyes e imaginarios sociales en torno al indio}

El Protector iniciaba la defensa del caso indicando que a la fecha -año 1823probablemente no se había presentado un hecho criminal cometido por un "(..) individuo de la Nación de Economi y revestido de las mismas circunstancias que el presente ante los Tribunales (...),15. Aunque las fuentes judiciales puedan corroborar o no la veracidad de su afirmación, el uso del termino Nación probablemente se vinculaba a "la persistencia de una tradición colonial basada en el Derecho de Gentes que focalizaba en la concepción de los indios (situados más allá del Río Salado y de donde procedía el indígena protagonista de esta historia) en tanto nación soberana e independiente respecto de la del blanco" ${ }^{16}$. Este reconocimiento se vinculaba con la política indígena borbónica que buscaba transformar a los grupos étnicos en sus súbditos y a cambio de esa lealtad absoluta hacia la Corona, les ofrecía gozar de autonomía territorial y política como así también de protección legal. No obstante, se plantea que durante la década revolucionaria y principalmente en los años de 1820, ciertos tratados firmados con algunas parcialidades nativas, dejaban entrever la emergencia de otra postura negadora del status de nación soberana asignado a los indígenas. Ya hacia 1825, cuando el gobierno de Buenos Aires encomendó a Juan Manuel de Rosas iniciar negociaciones con los indios de las pampas, a medida que éste avanzaba en las mismas, iba atribuyendo a aquellos un nivel de subordinación y de dependencia hacia su persona, que le permitió acceder a las paces y con ello, fue desapareciendo la noción de grupo soberano ${ }^{17}$.

Lo cierto es que en congruencia con aquella visión de la entidad indígena como Nación, el abogado defensor expresada claramente que: (...) no hallándose su protegido en curso en las penas que imponen las Leyes de esta sociedad, se ha de servir VS

\footnotetext{
${ }^{15}$ AHPBA. Juzgado del Crimen. 34-3-48-13.

16 Ibidem.

17 Ratto, Silvia (2003). “¿Soberanos, "clientes” o vecinos?: algunas consideraciones sobre la condición de los indígenas en la sociedad bonaerense”. In Villa, D.; Jiménez, F. y Ratto, S. (Ed.) (2003). Conflicto, poder y justicia en la frontera bonaerense, 1818-1832, Bahía Blanca y Santa Rosa: Universidad Nacional del Sur y Universidad Nacional de La Pampa, p. 145-164.
} 
(Vuestra Señoría) de absolverlo según las razones que paso a exponer (...)" (la aclaración me pertenece). En el marco de tales razones y de la posición ideológica plasmada en su discurso, uno de los argumentos axiales -aunque no exclusivo- en el que basó la defensa, fue la afirmación de que Economi desconocía las leyes y penalizaciones de la sociedad blanca y en consecuencia, había actuado según las normas y costumbres del sistema indígena de procedencia:

(...) Economi ignoraba la existencia de alguna Ley que imponga pena al que mata a otro, y que sólo sabe que entre los indios, el que quita la vida, no tiene más deber que notificárselo a un Cacique, ni tiene más pena que pagar con sus bienes, un tributo a los deudos del "ofendido", y si es pobre, declarar la guerra a los parientes de aquel que ha muerto, poniéndose en defensa y asociado con los que está ligado (.... $)^{18}$.

Como ya hemos señalado, la modalidad de resolución de conflictos en la sociedad indígena, presentaba especificidades propias y la figura del Cacique adquiría un rol de justicia fundamental. Asimismo, cuando los indios protagonizaban conflictos en jurisdicción hispanocriolla, las autoridades bonaerenses podían buscar la solución apelando a una conciliación entre prácticas pertenecientes al sistema judicial provincial y al de los indígenas, lo cual generaba una imprevisibilidad en la resolución de los conflictos. Inclusive, solía acudirse a diversas formas de infrajudicialidad, entendidas como mecanismos de arbitraje, basados en distintos modos de compensación de la acción delictuosa, que operaban fuera de los juzgados y se apoyaban en normas y valores consuetudinarios. Por lo tanto, aunque los dos sistemas de aplicación de justicia se complementaban, implicaban formas diferentes de sentenciar los delitos: los indígenas recurrían a mecanismos de mediación a fin de lograr un acuerdo entre las partes y que ambas queden en absoluta conformidad con lo resuelto, en tanto el sistema occidental buscaba identificar culpables y víctimas ${ }^{19}$.

En esta dinámica, era posible percibir al Cacique, de cuya toldería procedían los indios acusados, intercediendo por éstos ante las autoridades de Buenos Aires, participando activamente del proceso judicial, aceptando ser interrogado e inclusive permitiendo que oficiales de policía e intérpretes ingresaran a su tribu a indagar a los indígenas ${ }^{20}$. Es decir, el jefe funcionaba como un intermediario cultural, denominación que designa a individuos que -en las áreas centrales y en los espacios de frontera- por su

\footnotetext{
${ }^{18}$ AHPBA. Juzgado del Crimen. 34-3-48-13.

${ }^{19}$ Farberman, Judith; Ratto, Silvia (Coord.) (2009). Historias mestizas en el Tucumán colonial y las pampas (siglos XVIII-XIX), Buenos Aires: Biblos.

${ }_{20}$ AHPBA. Juzgado del Crimen. 34-2-37-1.
} 
posición económica, política, social, cultural, religiosa, actuaban como mediadores entre el mundo indígena y el hispanocriollo, ya que se encontraban favorablemente posicionados en ambas sociedades. Estos personajes podían ser cronistas, misioneros, mestizos, caciques, renegados, entre otros, que al compartir elementos de ambas culturas, como por ejemplo el lenguaje, podían actuar bajo diversas circunstancias. En este sentido, los cultural brokers funcionaron como puente para la convivencia interétnica, actuando algunos (vecinos, militares de frontera y lenguaraces) como interlocutores de comitivas diplomáticas dentro del espacio indígena ${ }^{21}$.

En el caso del indígena Francisco Economi, no existió la intermediación de una autoridad cacical; por el contrario, si bien -en términos del defensor- el imputado “(...) pertenece a la sociedad de los indígenas que siguen religión natural y no tienen más Leyes que las de la naturaleza impresas en el corazón de todos los hombres que habitan el Globo (...),22, a la fecha vivía en Buenos Aires, no por haber renunciado a su sociedad de origen ni "a sus costumbres bárbaras" ni tampoco a sus leyes sino "a la fuerza y aprisionado en la guerra": para Economi, no existían en el mundo más leyes que "esas costumbres bárbaras" típicas de los indios. En un caso como éste donde

(...) al homicidio lo ha perpetrado en un hombre de su misma sociedad y religión (...)" y consecuentemente "(...) sus derechos y deberes -o como se quieran llamar entre los indígenas- son iguales, esta sociedad no puede quejarse de su crimen en cuanto este miembro no le pertenece ni ha violado sus Leyes (... $)^{23}$.

Inclusive, en su apelación posterior, el protector afirmaba que Economi hubiera tenido culpabilidad, únicamente si al crimen lo hubiese perpetrado en la persona de un ciudadano de Buenos Aires: “(...) Él (Francisco Economi) sufriría la pena de la ley, si hubiese quitado la vida a otro que un paisano suyo (...) no existe el derecho que la sociedad puede tener a penar unas partes que no entran en el todo de nuestra sociedad $y$ cuando más se hallará que ella puede castigar a los que quebrantan las seguridades que ella ha prometido a sus ciudadanos (...)" (la aclaración me pertenece).

La defensa se fundaba en el convencimiento explícito de que las leyes impuestas por el órgano jurisdiccional de la provincia, no podían castigar el acto criminal del indígena

\footnotetext{
${ }^{21}$ Para un análisis detallado sobre este tema, véase Ratto, Silvia (2005). Caciques, autoridades fronterizas y lenguaraces: intermediarios culturales e interlocutores válidos en Buenos Aires (primera mitad del siglo XIX). Disponible en: http://www.scielo.org.ar/scielo.php?script=sci_arttext\&pid=\$1515-59942005000100008. Consulta: el 7 de mayo de 2008.

${ }_{22}^{22}$ AHPBA. Juzgado del Crimen. 1823: 34-3-48-13.

${ }^{23}$ Ibidem.
} 
porque éste no las había quebrantado al no haberse sometido a ellas, y que el cumplimiento de los derechos, deberes y obligaciones debía ser exigido a todos los miembros de la "civilización", especialmente los "hombres cultos", conocedores y aceptadores de las normativas sociales y legales vigentes. Así, el Protector trazaba una tajante escisión entre éstos y el imputado, distinguiéndolos humana y culturalmente:

(...) las leyes que nos goviernan obligan a aquellos individuos que han venido a nuestro pago voluntariamente y por el mismo hecho se han sujetado a las obligaciones que les imponen y penas en ellas establecidas, y no pueden ignorar el Derecho por pertenecer a naciones civilizadas, tienen nociones generales de lo que es bueno o malo y de lo que es prohibido y permitido. Últimamente sus costumbres con las nuestras sino son idénticas hay una diferencia poco notable; pero ¿cómo podrá encontrarse un símil entre Ecónomi y los demás hombres cultos o que pertenecen a naciones civilizadas? $(\ldots)^{24}$.

\section{III.a- La dicotomía "civilización y barbarie: ¿una estrategia jurídica?}

En estrecha relación con lo dicho hasta aquí, el Protector General de Pobres consideraba a su defendido como "(...) un habitante de los Desiertos, sin domicilio porque los indios barbaros viven errantes, sin Gobierno ni Leyes porque no forman estado, sus costumbres analogas á su modo de vivir, son distintas (a las del blanco) y peculiares a ellos (...)". Conforme a ello, en la posterior apelación interpuesta ante la sentencia condenatoria del juez, nuevamente recurríría al imaginario colectivo alegando que el indio Economi se trataba de un hombre "(...) arrancado de las hordas salvajes y en quién la educación, los usos y costumbres bárbaras de su país, tal vez han borrado hasta aquellos primeros principios de Derecho Natural (...) ${ }^{25}$. (Los remarcados y la aclaración me pertenecen).

Estas concepciones, se basaban en una idea abstracta de "el indio" como bárbaro, sangriento y criminal, bruto e ignorante o falto de cultura ${ }^{26}$. $Y$ en este punto, no podemos obviar qué se entendía por "indio" y en definitiva de dónde procedía esta categoría estrechamente vinculada a tales rasgos atribuidos en la defensa. La categoría colonial de "indios" fue aplicada a toda la población americana sin excepción y sin reconocer las identidades preexistentes o prehispánicas. Si bien es utilizada de manera general, ha sido

\footnotetext{
24 Ibidem.

${ }^{25}$ Ibidem.

26 Quijada, Mónica (2001). "Indígenas: violencia, tierras y ciudadanía”. In Quijada, M.; Bernand, C.; Schneider, A. (2001). Homogeneidad y Nación con un estudio de caso: Argentina, siglos XIX y XX, Madrid: Consejo Superior de Investigaciones Científicas. Centro de Humanidades. Instituto de Historia, p. 57-92.
} 
objeto de un largo debate historiográfico que no se agotaría en estas páginas. Por eso, sólo mencionaremos brevemente algunas consideraciones centrales en torno al término.

Para Bonfil Batalla, indio "es una categoría supraétnica que no denota ningún contenido específico de los grupos que abarca, sino una particular relación entre ellos y otros sectores del sistema social global del que los indios forman parte (...) Denota la condición de colonizado y hace referencia necesaria a la relación colonial’27. Según este autor, la heterogeneidad interna de las poblaciones indígenas quedó anulada desde el inicio mismo del proceso de conquista porque se enmascaró su especificidad histórica y se las transformó en un ser plural y uniforme: el indio/los indios al interior del orden colonial. Es decir, define al "indio" en base a su condición de colonizado o bien de dominado.

En realidad, se ha planteado que existe una confusión en relación al origen y la función real del concepto en cuestión. El origen es conocido, surge a partir de que Colón y su expedición creyeron haber llegado al lugar que habían previsto: Las Indias, y aunque no fue así, igualmente permaneció el nombre de indios para referirse a la población del continente. Pero al español lo que verdaderamente le importaba era que estos grupos fueran diferentes del colonizador y en este sentido, la función del concepto de "indio" era la de discriminación; así, la categoría "indio" poseía un contenido ideológico discriminatorio que lo hacía inferior y, por lo tanto, sujeto de dominación, siendo aplicada a los diversos grupos culturales encontrados a la llegada del conquistador a América ${ }^{28}$. Por ello, Gallego Vázquez define a los indios como "una serie de grupos socioculturales que se reconocen entre ellos mismos, y son reconocidos por los demás como descendientes de las culturas prehispánicas y que se identifican como iguales, no por que tengan una cultura homogénea, sino por su condición de dominados en función de la ideología discriminatoria que se tiene hacía ellos". Para este autor, son las relaciones de dominación y no las coloniales, las que definen al indio.

En suma, la peculiaridad histórica de la definición de la categoría indio, en términos de identidad, es que fue instituida desde fuera por el colonizador, portando así una carga peyorativa y discriminatoria; era utilizada siempre por los otros y la autoidentificación se

\footnotetext{
${ }^{27}$ Bonfil Batalla, Guillermo (1972). "El concepto de indio en América. Una categoría de la situación colonial". In Anales de Antropología, v. 9, p. 110.

${ }_{28}$ Gallegos Vázquez, Rafael (2003). "Los conceptos "indio" y "ladino": construcciones histórico sociales definidas por sus relaciones". Disponible en:

http://www.url.edu.gt/PortalURL/Archivos/83/Archivos/Departamento\%20de\%20Investigaciones\%20y\%20pu blicaciones/Articulos\%20Doctrinarios/Pol\%C3\%ADticas/Conceptos\%20de\%20indio\%20y\%20ladino.pdf. Consulta: el 19 de diciembre de 2011.
} 
hacía respecto de un grupo étnico específico (como pampas, mayas, etc.), diluyéndose así las diferencias entre los distintos grupos étnicos y colocándolos en una posición de inferioridad. Desde esa connotación negativa, nadie se reconocía como tal, aunque sí los propios indígenas. Con esa carga peyorativa, la autopercepción del indígena como tal se constituía en la asimilación de la ideología dominante que lo sitúa en el grado más bajo de la escala social ${ }^{29}$.

Hecha esta salvedad, podemos afirmar que, distando de aquellos constructos ideológicos presentados por la defensa, los indígenas desarrollaron complejas estructuras sociales, económicas y políticas; procesos de diferenciación social, de acumulación de riqueza, de formación de grandes unidades políticas (los cacicatos), de concentración de autoridad en los grandes jefes, tuvieron lugar durante los siglos XVIII y XIX ${ }^{30}$.

Sin duda, el defensor estaba apelando a un discurso cargado abiertamente de prejuicios y estereotipos negativos, plasmados en las expresiones estigmatizantes de "indios bárbaros" para referir al grupo social de Economi; "habitante de los Desiertos" en contraposición a los "hombres cultos o que pertenecen a naciones civilizadas", haciendo también alusión al "estado de naturaleza o salvaje". La calificación de salvaje no difería demasiado de la de bárbaro y ambas compartían un tono desacreditador, connotando (des)valorizaciones y relaciones interpersonales de desigualdad, tendientes a la inferiorización de la Otredad indígena.

Así, la utilización del concepto de bárbaro en los alegatos del abogado defensor, portaba una carga que, aplicada al imputado, lejos de ser imparcial resultaba valorativa englobando los atributos de primitivo, inculto, ignorante, todas apreciaciones etnocéntricas. En términos de Barabas, el bárbaro representa el opuesto a un nosotros colocado en la posición de superioridad y hegemonía: por definición, es un Otro percibido como diferente a partir del que observa y relata, y el etnocentrismo exhibido por este concepto, es un componente fundamental para la construcción contrastativa de la identidad propia, ya que la delimita y define por oposición ${ }^{31}$.

A su vez, aquella consideración de Economi como un "habitante de los Desiertos", perteneciente a un grupo errante y carente de organización política concreta -de la que el Protector negaba tuviera Leyes-, se contraponía a los sujetos cultos de las "Naciones

\footnotetext{
${ }^{29}$ Revilla Blanco, M. (2005). "Propuesta para un análisis del movimiento indígena como movimiento social". In Política y Sociedad v. 42, n. 2, p. 49-62.

${ }^{30}$ Mandrini, Raúl (1992). "Indios y fronteras en el área pampeana (siglos XVI-XIX). Balance y perspectiva". In Anuario IEHS, n. 7. p. 59-73.

${ }_{31}$ Barabas, Alicia (2000). "La construcción del indio como bárbaro: de la etnografía al indigenismo". In Alteridades v. 10, n. 19, p. 9-20.
} 
Civilizadas" entre las que se incluía a la sociedad bonaerense. De este modo, en el discurso de la defensa, la barbarie se asimilaba a otro atributo negativo propio del imaginario colectivo: el "Desierto". Tal como afirma Monica Quijada, uno de sus significados lo asociaba a un espacio "bárbaro" que en tanto tal generaba "barbarie"; civilización era lo urbano y lo europeo, fueran personas, ideas o sistemas sociales; la barbarie, representaba el resto: todo lo que no era civilizado resultaba "bárbaro" o "salvaje". En simultáneo, el "desierto", desde la perspectiva de la construcción del Estado, también refería a los espacios no controlados por el poder central y a la consecuente necesidad de una integración territorial que expandiera monopólicamente el dominio de las instituciones por todo el territorio argentino. Precisamente, más allá de la frontera natural del Río Salado, se extendía aquella área no controlada por la "civilización" sino ocupada por las tolderías, y concebida durante el siglo XIX, como humanamente vacía o con una población indigna y salvaje; de allí que fueran consideradas como "desiertos" o "baldíos"32. Existía una construcción de las pampas como pobres, improductivas y con limitaciones para la ocupación humana. Pero lejos de conllevar estas características, La Pampa fue un ambiente altamente propicio para el asentamiento del Hombre que, desde el Pleistoceno Final hasta los tiempos posthispanicos, mantuvo la forma de vida cazadorarecolectora, desarrollando una significativa variabilidad cultural. Precisamente, el indígena Francisco Economi procedía de alguna toldería del Arroyo de Chapaleufú, al interior del estigmatizado contexto pampeano.

En verdad, la postura del Protector era muy clara:

(...) El Defensor absteniéndose de agitar la question, sobre si en el estado de naturaleza ó salvaje era licito ó permitido matar y en $q^{e}$ circunstancias, cree $q^{e}$ con lo expuesto basta $p^{a}$ convencer a V.S $q^{e}$ Economi no ha infringido las Leyes vigentes por lo siguiente la sancion penal no debe recaer sobre el (....33.

Acto seguido y conforme a su postura legal e ideológica, advertía sobre la no pertinencia de nombrar un defensor, el cual debería haber sido designado sólo si a Economi le hubiera correspondido ser juzgado con arreglo a las leyes vigentes por haberlas incumplido, pero no en este caso por los motivos antes expresados: “(...) Sin embargo, de cuanto se ha expuesto para no dexar vacío alguno á la defensa, el Defensor se pone en el caso que Economi deba ser juzgado con arreglo a las Leyes vigentes $p^{r}$. que las ha infringido(... $)^{, 34}$. No obstante la aclaración, la defensa prosiguió por vías más

\footnotetext{
${ }^{32}$ Barabas, A. (2000). Op. cit.; Quijada, M. (2001). Op. cit.

${ }^{33}$ AHPBA. Juzgado del Crimen. 34-3-48-13.

34 Ibidem.
} 
técnicas que las anteriores. Consideraba que los únicos con conocimiento de causa ignoraba a Luciano Guenchín como testigo presencial- habrían sido el ofendido y Economi, y que al no poder atestiguar la víctima, el único relato verídico sobre cómo ocurrieron los hechos, debía ser el de Economi. Entonces, al resultar que los indios en rivalidad se encontraban embriagados, para averiguar quién había sido el provocador y causante era necesario -desde la óptica del defensor- valerse del relato de Economi, al que situaba en la posición de un hombre "bien intencionado" que admitió haber herido a Queuna sólo en defensa de "un compañero y amigo" (Luciano Guenchin). Por ello, el abogado negaba la condición de delincuente de su defendido estableciendo que éste no había incurrido en ninguna acción culposa. Luego, fue desacreditando las acusaciones que, en el marco de las declaratorias obrantes en el expediente, comprometían profundamente al indígena Francisco Economi.

En este sentido, para el Protector General, el testimonio de Luciano Guenchin quedaba rebatido por la declaración de su defendido y no merecía crédito por dos razones: la primera, por hallarse el testigo tan embriagado como los otros y en incapacidad de orientarse a las circunstancias del hecho, y la segunda, por ser "inhábil debido a su edad", ya que sólo poseía 18 años y acorde con la Ley, los testigos de las causas criminales debían ser mayores de 20 años. En consecuencia, la exposición de Guenchín era considerada "nula y carente de valor". Sin embargo, las circunstancias de embriaguez del testigo mencionadas por el Protector, no aparecían en el sumario por lo cual la atribución de un estado alcoholizado pudo haber sido tan sólo un recurso más de la defensa para desacreditar el testimonio.

Por todo lo propiamente dicho y atendiendo a la pena solicitada, consideraba que

(...) La pena de cinco años contra mi protegido es aplicable a aquellos hombres que embriagados provocan y hieren de muerte (...) del sumario no consta que Economi haya sido provocador ni menos que haya dexado de poner todo aquel cuidado que debía para no dañar, por consiguiente, la pena es injusta. Habiéndose demostrado con convencimientos irresistibles que Economi no está incurso en las penas que imponen nuestras leyes, y aunque por ellas debiera ser jusgado, la pena de cinco años de presidio á ración y sin sueldo con destino á las obras públicas no solamente es desproporcionada sino ilegal, la absolución es de rigurosa justicia $(\ldots)^{35}$.

\footnotetext{
${ }^{35}$ Ibidem.
} 


\section{III.b- Un comentario acerca de la defensa}

Los alegatos culturales y procedimentales accionados por la defensa, permiten pensar en la coexistencia de dos partes netamente diferenciadas entre sí aunque vinculadas: una inicial, equivalente a un discurso social y cultural, cuyos fundamentos estuvieron basados en el imaginario estigmatizante sobre el indio. La otra, propiamente legal y ya no aferrada a un imaginario, estuvo centrada en las pruebas y los testimonios obtenidos. Es innegable que la exposición inicial de argumentos, razones y pruebas en favor del acusado, conllevaba una mirada a la Otredad desde "Ios lentes distorsionadores" de la ideología racista de la época, es decir, la ignorancia del hombre sobre sus semejantes por falta de información y por las nociones a priori, los prejuicios y los intereses encubiertos, donde todo hallaba justificativo en la supuesta superioridad que el blanco creía tener por sobre los otros grupos étnicos. Desde esta óptica, los hábitos, usos y costumbres socioculturales del contexto de procedencia del indígena, eran inscriptos en la barbarie y por ello, la defensa consideraba que habían obrado negativamente en Economi diluyendo hasta los principios y normas esenciales del Derecho Natural, reguladores de la conducta humana.

Sin embargo, creemos que los descalificativos hacia el indígena marcando una absoluta división entre "indios y blancos", "barbarie y civilización", lejos de representar una realidad concreta al interior de la sociedad local, funcionaron más como una estrategia jurídica orientada no tanto a probar la inocencia del indígena porque el delito había sido corroborado, sino a lograr su absolución. Inclusive, argumentaba que si Economi se hubiera persuadido de que podía demandar y ser demandado ante los tribunales de Buenos Aires, sin duda no hubiera cometido el crimen y menos aún teniendo en cuenta el "notable temor" que acompañaba a los indígenas desde que ingresaban a los pueblos del blanco creyendo estar reputados como enemigos declarados.

En realidad, todas las construcciones simbólicas esgrimidas por el defensor, se desvanecen cuando se las somete a un análisis serio. Efectivamente, las sociedades indígena y blanca no constituyeron mundos aislados y separados, sino que existió una frontera "porosa" con el indio, donde "nos encontramos ante todo con una multiplicidad de situaciones imprecisas y con constantes transferencias de un universo a otro". Cada avance del blanco, englobaba e incorporaba en su seno a indígenas que pasaban a 
formar parte de la población, integrados en el sistema productivo ${ }^{36}$. Los indios y blancos establecieron una compleja red de relaciones que no estuvieron limitadas a los conflictos bélicos y se vertebraron en torno al comercio. A través del mismo, diversas influencias culturales (hábitos, usos y costumbres) propias del blanco, penetraron en la sociedad tribal al tiempo que los pobladores de la frontera adoptaban numerosos elementos de los indios. Esta dinámica recíproca implicó la existencia de cristianos o huincas -desertores, delincuentes, fugitivos, cautivos- que vivían en las tolderías de manera permanente o temporal, y de indígenas que en grupo o individualmente se establecían cerca o dentro del territorio blanco, algunos de los cuales lograron integrarse ${ }^{37}$.

Estos "trasvases culturales" -en términos de Mónica Quijada- permitieron ver al indio no como un mero espectador y receptor pasivo de las acciones de los blancos sino trabajando junto a criollos, migrantes e individuos de otras castas e "intentando reproducir sus patrones culturales en un contexto social diferente que lo llevaría a modificar, en parte, esas prácticas". En ese sentido, la frontera debe pensarse como un área multicultural, de interrelación entre los distintos grupos que la habitan y los grandes flujos de migración indígena, mestiza y mulata evidenciados en las actas de matrimonio, quebrantan la imagen de "ciudad blanca" con núcleos de gente de color rigurosamente separada del resto por el vínculo de la esclavitud que ostentaba Buenos Aires ${ }^{38}$.

En este sentido, existió un proceso de interacción étnica en todas sus expresiones desde los primeros tiempos de la Conquista, y una faceta del mismo fue la mestización de los grupos que entraban en contacto. Como es sabido, el fenómeno del mestizaje asume una naturaleza dual; por un lado, puede presentarse como el resultado de procesos violentos de mezcla, entre los que destacan la procreación de hijos engendrados por la fuerza, la deculturación, la intolerancia de la alteridad y la perdida de identidad y derechos, y el etnocidio. Pero, por otro, puede ser producto de la integración óptima (no conflictiva ni forzada) y consistir en un proceso espontáneo. En este sentido, en la introducción de su libro Historias mestizas, Silvia Ratto y Judith Faberman, presentan el estado de la cuestión en torno a los procesos bio-culturales de mestizaje desarrollados tanto en las áreas centrales del dominio colonial como en los espacios fronterizos, y describen el cambio axiológico y consecuentemente de posicionamiento social y jurídico,

\footnotetext{
${ }^{36}$ Quijada, Mónica (2002). "Repensando la frontera sur argentina: concepto, contenido, continuidades y discontinuidades de una realidad espacial y étnica (siglos XVIII-XIX)". Disponible en:

http://digital.csic.es/bitstream/10261/8769/1/REPENSANDO\%20LA\%20FRONTERA\%20SUR\%20ARGENTI

NA.pdf . Consulta: el 1 de abril de 2012.

${ }^{37}$ Mandrini, Raúl (1992). Op. cit.

${ }^{38}$ Farberman, Judith; Ratto, Silvia (Coord.) (2009). Op. cit., p. 24- 41.
} 
que fue experimentando la percepción del mestizaje (y de los mestizos) al interior de la sociedad colonial ${ }^{39}$.

\section{IV- La apelación del Protector General de Pobres}

El Juez de Primera Instancia consideró que aquellas argumentaciones expresadas en la defensa, estaban construidas sólo a conveniencia del reo Francisco Economi y no corroboraban su inocencia. De este modo, el magistrado fue contundente y declaró que

(...) el Agente del Crimen ha probado bien su acusación; y que el acusado, y por el su defensor no lo han verificado de sus exenciones y defensas como les convenía (...) que devo condenar y condeno al expresado Indio Conomi a la pena de cinco años de presidio, destinado a los trabajos públicos a racion y sin sueldo y contados desde el dia de su prision. Que por esta mi sentencia definitiva asi lo pronuncio y firmo ${ }^{40}$.

De esta manera, se rectificaba la sentencia solicitada por el Agente Fiscal. El Protector, consideró injusto el fallo e interpuso un recurso de apelación ante la Cámara de Justicia para que ésta conceda la revocación inmediata de aquel. En su apelación, calificó de agraviante lo pronunciado por el Juez y en parte, reiteró algunos alegatos defendidos con anterioridad, posiblemente a fin de remarcar posturas que resultasen convincentes en el marco del proceso penal. Pero también, en esta nueva instancia del proceso, reforzó una cuestión desatendida en la primer defensa -la atribución al reo del delito por ebriedade introdujo un nuevo elemento como justificativo del crimen: las eventualidades por las que el indígena se había separado de su toldería. En principio, explicaba que Economi

(...) no vino a buscar su suerte en nuestro país, no es un hombre que lo ha traído la guerra y que en ella se ha hecho prisionero. De cualquiera de estos modos que él hubiese llegado aquí, ó se sujetaba voluntariamente a nuestras leyes, o se había espuesto a estar á los mandatos de su vencedor $(. . .)^{41}$

Las verdaderas circunstancias por las cuales el reo había arribado a Buenos Aires, se vinculaban con el hecho de que

\section{(...) El governador $D^{n}$. Martín Rodríguez cuando abrió la campaña contra los}

\footnotetext{
${ }^{39}$ Ibidem, p. 9-26. Basándose en trabajos de autores como Magnus Morner, Ana María Presta y Berta Ares Quijada, se plantea que la mezcla de indio y español no fue inicialmente rechazada e inclusive los hijos nacidos de la unión entre las mujeres de la nobleza indígena y los conquistadores, se transformaban en excelentes partidos para otros españoles de linaje distinguido. Sin embargo, esta situación cambió y ya entrada la segunda mitad del siglo XVI, sobre los mestizos recaía la ilegitimidad de su nacimiento y su condición generalizada de huérfanos, aspectos que los segregaban respecto de la élite, siendo degradados por la procedencia indígena y subalterna de la madre.

${ }^{40}$ AHPBA. Juzgado del Crimen. 34-3-48-13.

${ }^{41}$ Ibidem.
} 
salvajes de Sur, trajo á este pueblo muchos indios pacíficos: y Economi viniendo de enviado del Cacique de algunos que habían logrado retirarse, lo hizo pasar el Gobernador á este pueblo en clase de prisionero. No hay pues un acto del $q^{e}$ no manifiesta que quizo entrar en nuestra sociedad, ni un por qué lo juzguemos como a prisionero de guerra, ni como a un estrangero $q^{e}$ recide, ni aunq ${ }^{e}$ pasa por nuestro país, ni $p^{r} q^{e}$ le comprenda la cédula de $82(\ldots)^{42}$

Sin dudas, el Protector estaba aludiendo a una realidad de aquel tiempo y de la que Economi resultaba ser un protagonista más: la problemática del indio en la frontera. Tal como plantea Raúl Mandrini ${ }^{43}$, los vínculos relativamente pacíficos entablados con la población indígena durante la segunda década del siglo XVIII, se quebrantaron a partir de 1820, debido a la reorientación de la economía porteña hacia una ganadería extensiva. Hasta ese momento, los gobiernos revolucionarios habían conservado la política tardocolonial a fin de mantener la paz con los indios, ya que las guerras con la independencia primero y los conflictos regionales después, desprotegían militarmente al espacio fronterizo. Pero desde 1820 y durante casi una década y media, las relaciones entre ambas sociedades se tornaron cada vez más violentas a medida que crecía la competencia por tierras y ganado.

Cuando Martín Rodríguez asumió el gobierno de Buenos Aires, impulsó acciones políticas tendientes a la expansión ganadera y comercial, en el marco de un nuevo proyecto institucional de crecimiento, lo cual implicó la necesidad de expandirse territorialmente sobre las áreas controladas por las parcialidades étnicas. Con ese objetivo, inició campañas contra los indios -y a las cuales dirigió personalmente- atacando en primer término las tolderías del Cacique Ancafilú en las riberas del Arroyo Chapaleufú de donde procedía Francisco Economi. No obstante, los indígenas lograron escapar y sólo algunos pudieron ser tomados prisioneros aunque mediante esas actuaciones, el gobernador violaba el Pacto de Miraflores. El mismo, era una convención entre la Provincia de Buenos Aires y los caciques de la frontera del sur, que Rodríguez -siendo sólo Comandante General de la Campaña- había firmado con los indios tiempo atrás (marzo de 1820). En la negociación participaron Ancafilú, Tucumán y Tricnín, autorizados previamente por otros caciques para representarlos en las tratativas con el gobierno. El acuerdo había ratificado la paz en el territorio y declarado como línea divisoria definitiva, la alcanzada por los hacendados de las estancias al sur del río Salado. Sin embargo, sobrevinieron conflictos consecuencia de repetidos malones que contribuyeron a

\footnotetext{
42 Ibidem.

${ }^{43}$ Mandrini, Raúl (2008). La Argentina aborigen. De los primeros pobladores a 1910, Buenos Aires: Siglo XXI Editores.
} 
desmoronar aquel acuerdo al tiempo que determinaron el inicio de las expediciones contra los indios por parte del gobernador.

Por ello, el Protector General sostenía que si bien el gobierno provincial se había visto obligado a tomar prisionero a un hombre, en el marco de las campañas referenciadas, esto no significaba haber introducido en la sociedad a un individuo como Economi que podía cometer homicidios bajo la garantía de sus bárbaras costumbres: en este punto, aún reconociendo que nada justificaba legalmente la comisión del crimen y dejando implícita la idea de que Economi, pese a ser un prisionero del gobierno, no debía integrar la sociedad blanca si portaba conductas peligrosas, igualmente se propuso rebatir la culpabilidad por ebriedad atribuida por el Fiscal. El abogado defensor consideraba a la ebriedad no un impedimento para comprender la criminalidad del acto, sino un hábito permitido de la sociedad indígena, de modo que al ser inherente a la cultura y naturaleza de su representado, no implicaba culpa ni debía ser penalizada por la sociedad del blanco. En este sentido, el abogado presentó circunstancias y argumentos relativos a la cultura y costumbres de su protegido, en un intento por favorecer la idea de que éste no había actuado con premeditación sino tan sólo siguiendo sus costumbres tribales. Además, advertía que la ebriedad -y el hábito de la bebida- eran rasgos frecuentes entre la población indígena que vivía integrada entre los blancos.

En la defensa de algunos casos, aparece la conveniencia legal de utilizar el pretexto de la embriaguéz como atenuante del delito y los sugestivos alegatos de los protectores hacían pensar que algunos indígenas que echaban la culpa de sus actos al alcohol, estaban pronunciando palabras en las que no creían, pero los jueces tenían muy claro que los indios -como Economi en su declaración indagatoria- podían hacer valer el alcohol en su beneficio como excusa de sus agresiones ${ }^{44}$. El Protector argumentaba que una ley de partida en Buenos Aires, castigaba al homicidio cometido en embriaguez, con la condena de cinco años de prisión porque intervenía culpa por parte del homicida en el hecho mismo de cometer una acción mala (la de embriagarse) y de exponerse a otros delitos peores (como el matar). En este sentido, indicaba que en una sociedad regularmente ordenada, los hombres veían todos los días castigar a los ebrios y aunque su razón no les dictaba que el alcoholizarse era de por sí malo, sabían que estaba prohibido, que faltaban a un derecho positivo y en ésto residía la culpa. A diferencia, su defendido se distanciaba de esta regla, ya que un individuo como Economi, ignorante

\footnotetext{
44 Taylor, William (1987). Embriaguez, homicidio y rebelión en las poblaciones coloniales mexicanas,
} México: Fondo de Cultura Económica. 
también de este mandato y para el cual el embriagarse representaba un "placer permitido", no cometía culpa en ello. Por lo tanto, aquellas normas endilgadas como trasgredidas para las leyes de Buenos Aires, no lo estaban para el Protector quién argumentaba que, en el caso particular de su defendido:

(...) nosotros no podemos saber hasta que extremo de oscuridad puede haber llegado la razón de un hombre en quién por más de 50 años, han "señoreado" las pasiones, $y$ si es cierto que los primeros principios del Derecho Natural son unos mismos entre todos los hombres y entre todas las naciones, sus derivados no lo son, y aunque el reo hubiese cometido una culpa en embriagarse, no sería de la misma clase que la que cometiese otro hombre, para que la Ley que rige con uno, deba también aplicársele al otro, siendo así que no hay el mismo grado de malicia. Hace más de dos años que este infeliz está sufriendo una esclavitud bastante dura y su suerte triste merece de VS alguna consideración por la misma razón de no agravar tantos males que sin duda pasan sobre este desdichado $(\ldots)^{45}$.

Estos argumentos tuvieron un efecto favorable en el veredicto final porque el Juez redujo dos años de prisión respecto de los cinco originalmente solicitados por homicidio y ebriedad, conservando el destino del reo a las obras públicas a ración y sin sueldo. En suma, se ordenaba la devolución del indígena Francisco Economi a las tolderías, tras la finalización de su condena. Es imposible comprobar si realmente retornó a su toldería de origen; podría pensarse que sí, considerando aquella orden judicial y también las afirmaciones del abogado defensor sobre las relaciones que el reo conservaba con su sociedad y las circunstancias "forzadas" por las que llegó a Buenos Aires. Respecto a situaciones de este grosor, es interesante el planteo de Mónica Quijada de que el indígena anónimo, que traspasaba las fronteras abandonando lo que Mandrini denominó "el área de control indígena" (espacio efectivamente dominado por los indios) y se establecía en territorio del huinca con trabajo y familia, posiblemente no retornaba a su sociedad de origen. Es decir, en algunos casos, se perdían dichas relaciones con el grupo tribal en el proceso de integración y en otros, se mantenían ${ }^{46}$.

Finalmente, es imposible pasar inadvertidos, el lenguaje de los derechos (naturales) y la exaltación de las pasiones humanas, propiamente aludidos. Las consideraciones de la ebriedad basadas en la naturaleza pasional del hombre, respondían a una arraigada tradición iusnaturalista, heredada del mundo hispano, que reivindicaba la existencia de los derechos naturales, junto a otras corrientes intelectuales y que se reflejó claramente en el discurso de la defensa. Mariano Moreno por ejemplo, reconocía el peso de las pasiones en la condición humana pero creía en la posibilidad de moderarlas a fin

\footnotetext{
${ }^{45}$ AHPBA. Juzgado del Crimen. 34-3-48-13.

${ }^{46}$ Quijada, M. (2002). Op. cit.
} 
de poder "manejar con destreza las pasiones; ponerlas en guerra unas con otras, paralizar su acción; y dexar el campo abierto para que las virtudes operen libremente,47. Por supuesto, no intentamos teorizar sobre este tema, al cual retomaremos en el próximo apartado. Sólo mencionaremos brevemente -siguiendo a Beatriz Dávilo- que el reconocimiento de los derechos naturales (libertad, igualdad, propiedad y seguridad) representaba un asunto prioritario en las discusiones intelectuales y políticas de la época, enalteciéndose a la libertad como su principal valor. En este sentido, las cuestiones de las libertades individuales fueron las más fáciles de adaptar y aplicar en un contexto donde aún se hallaba fuertemente arraigada la herencia colonial, porque en el Río de la Plata no habían grandes masas de indígenas tributarios, en cuyo trabajo se sostuviera la economía. Al mismo tiempo, la igualdad, entendida como reciprocidad de la libertad, pudo materializarse en medidas concretas y se consideraba que "así como todos somos iguales ante el ser supremo, también lo somos ante la ley "48. Precisamente, a continuación analizaremos este principio de igualdad en relación al reo indígena Francisco Economi.

\section{V- La igualdad jurídica y los indígenas}

En términos del Fiscal de la Cámara de Justicia, no existía la menor duda de que el resultado del sumario comprobaba el homicidio y a su autor material y que el argumento de la apelación estaba centrado mayormente en torno a si las leyes penales de Buenos Aires eran o no aplicables al presente caso judicial. Acorde al Fiscal, las razones alegadas por el Protector General para sostener su postura, se desvanecían con tan sólo recordar que

(...) la ley natural nace con nosotros mismos e impresa con caracteres fijos en nuestros corazones, y $q^{e}$ esta ley constituye un tribunal interior que prohive, distinguiendo la naturaleza de nuestras obras, las malas, asi como hase sentir el placer delas buenas. La razón misma la humanidad grita en el corazón no matar a sus semejantes, y este derecho natural, ninguna nación, por varbara $q^{e}$ sea, le ha desconocido; asi es que el homicidio en todas es castigado y pocas noticias nos da la historia de una disposición en contrario; y ni aún de tolerancia, a que Economi se acoge por Ley entre los suyos $(. . .)^{49}$.

Evidentemente, para la institución judicial de Buenos Aires, los alegatos del Protector escasamente podían excusar a Economi de su responsabilidad en el crimen, ni siquiera aquellos basados en los principios del derecho natural. Frente a los mismos, la postura iusnaturalista del Agente Fiscal resultaba clara, ya que manifestaba

\footnotetext{
47 Véase Davilo, Beatriz. (2011). Los derechos, las pasiones, la utilidad. Debate intelectual y lenguajes políticos en Buenos Aires (1810-1827), Buenos Aires: EDUNTREF, p. 107.

${ }_{48}$ Ibidem, p. 84.

${ }^{49}$ AHPBA. Juzgado del Crimen. 34-3-48-13.
} 
(contrariamente al Protector General) que la ley natural -en su esencia de ordenamiento inmutable, que rige a los pueblos en todos los tiempos, que gobierna interiormente al hombre y que está formada por la naturaleza y la razón- opera al interior del ser humano permitiendo discernir lo que es bueno de lo que es malo. Por ello, desde este lado de la justicia criminal existía un convencimiento tácito de que aquellas reglas naturales regían para todos los pueblos y cada hombre, no existiendo sociedad alguna que no castigara el delito.

De hecho, un ejemplo de este último punto, fue el recordatorio del Fiscal al Juez acerca de un homicidio cometido tiempo atrás al interior del sistema indígena, cuyo autor material había sido efectivamente castigado. En este sentido, rememoró un caso de público conocimiento ocurrido hacia los años 1790-1794, en que un indio asesinó a su Cacique a orillas de la Guardia del Monte donde estaban acampados. La partida de indios notificó del hecho a una de las autoridades indígenas (no especificaba cuál) y el homicida recibió la sentencia de muerte. La misma, fue ejecutada en las inmediaciones de donde el agresor había cometido el crimen y consistió en alancearlo estando atado a un palenque. Por lo tanto, para el magistrado, las declaraciones de Economi -reiteradas por la defensarespecto a la inexistencia de penas y castigos para el homicidio en su sistema social de pertenencia, representaban un pretexto por estar únicamente sostenidas por su palabra.

Asimismo, desde la Cámara de Justicia, el Agente Fiscal establecía fehacientemente la pertinencia de aplicar el derecho positivo frente a todo crimen cometido al interior de la sociedad bonaerense, dictaminando que

(...) un habitante del país, sea cual fuese la causa que le haya conducido a él, queda sujeto a sus leyes civiles y penales mientras le habite, principalmente en las de homicidio, por ley natural y en las de hurto, porque reunidas las sociedades ya distinguieron la propiedad y se reputó un delito usurpar la agena (...) la pena que le ha impuesto el Juez de Primera Instancia es arreglada a la Ley y debe sufrirla por habitante del Estado sea cual sea el motivo por el que se halle en él: Por ello, se ha de servir VE confirmarla a la que a su superior estime más conveniente en Justicia (... $)^{50}$ (el remarcado me pertenece).

Es decir, la existencia de esa misma ley natural que entre otras cosas ordenaba al hombre no matar a sus semejantes, contribuía a favorecer el hecho de que el homicidio, sin dudas, podía y debía ser penado en el marco legal de la jurisdicción de Buenos Aires por ser en ella donde fue perpetrado-, con independencia de la procedencia tribal de la víctima y el victimario e indistintamente del motivo y tiempo de su residencia en Buenos

\footnotetext{
${ }^{50}$ Ibidem.
} 
Aires. Ya el periódico la Gaceta había aludido a una norma similar en 1810: "si alguno sea el que quiera nos inquietare o turbare arbitrariamente ó contra la disposición de la ley sufrirá en el momento la pena que ésta le imponga,61.

Por otra parte, si bien el Protector General había defendido que los hábitos, usos y costumbres del contexto de origen del indígena, estaban inscriptos en la barbarie y por ello, habían obrado negativamente en Economi diluyendo los principios y normas esenciales del Derecho Natural reguladores de la conducta humana, la interpretación jurídica del Juez y el Agente Fiscal fue diferente. Los mismos, consideraban que aquellos derechos naturales orientaban correctamente el comportamiento humano en todos los hombres sin excepción y debían conducir a la no violación del derecho positivo. Es evidente que lo dicho legislaba para toda la población y en la práctica se extendió al presente caso criminal sin distinciones étnicas.

Ahora bien, vale preguntarse ¿por qué el Fiscal hizo aquella lectura del caso criminal del indígena Economi y tomó tal resolución? En principio, podría pensarse que la disposición adoptada y la interpretación jurídica del Fiscal, estuvieron al unísono con los acontecimientos sociopolíticos y jurídicos del momento, a los cuales en parte hemos hecho alusión en apartados previos. Los mismos, tuvieron una gran influencia en las relaciones trazadas desde el gobierno con los indios, en un contexto orientado a la construcción de un nuevo orden social e institucional. Asimismo, desde el punto de vista de lo establecido por la legislación, conforme al ideario liberal de la Revolución, entre las modificaciones legales efectuadas, destacaron nuevas normas que afectaban directa e indirectamente a los indios. Se adoptó el principio de igualdad civil para todos los habitantes de las provincias que formaban el desaparecido Virreinato del Río de la Plata y por disposiciones expresas, este principio fue extendido desde los primeros instantes a los indígenas. Por decreto del $1^{\circ}$ de septiembre de 1811, la Junta Provisional Gubernativa resolvía: "Que desde hoy en adelante para siempre queda extinguido el tributo que pagaban los indios a la Corona de España en todo el territorio de las Provincias Unidas al actual gobierno del Río de la Plata y que en adelante se les uniesen y considerasen, bajo los sagrados principios de su inauguración,62. Posteriormente, La primera medida tomada por la Asamblea del Año XIII, fue la libertad de vientres bajo el fundamento de que "la naturaleza nunca ha formado esclavos sino hombres" y la esclavitud "ha tenido en

\footnotetext{
${ }^{51}$ Citado por Davilo, B. (2011). Op. cit., p. 64.

${ }^{52}$ Ibidem.
} 
consternación a la naturaleza desde que el hombre declaró la guerra a su misma especie". Aplicados estos principios a la población indígena de las Provincias Unidas, se abolieron la mita, la encomienda y el servicio personal, al tiempo que los indios eran declarados "hombres perfectamente libres y en igualdad de derechos a todos los demás ciudadanos que las pueblan”. La igualdad jurídica implica que todos los habitantes son iguales ante la ley, en idénticas circunstancias; que son juzgados por la misma ley.

A diferencia, la sociedad del Antiguo Régimen estaba construida sobre la base de la desigualdad reconocida por todos. En ella, la ley difería para cada estrato social, cuando no para cada persona, en una justicia del caso concreto, determinado según las desigualdades sociales definidas. La sociedad americana colonial se caracterizó por la existencia de diferentes status legales con fuertes privilegios corporativos. Pero impuestos con un status legal aún más específico para los grupos que la integraban, es decir, como relaciones de dominio sobre una sociedad multirracial de castas que afectaba particularmente a indios y a esclavos africanos. En consecuencia, en el ámbito de la justicia, un mismo hecho tenía penas distintas según la calidad (condición socioeconómica y étnica) del reo. En el período independiente, esta norma se modificó de modo que una conducta pasó a definirse como criminal independientemente del status social, la profesión y la condición étnica del acusado. Sin embargo, esto último no siempre se respetaba y algunas autoridades seguían aplicando la modalidad anterior ${ }^{53}$.

Si bien haberse independizado de España, no cambió repentinamente la naturaleza de la sociedad (ni de la justicia) -al tiempo que tampoco se gestó de inmediato una nueva matriz en la que la sociedad se organizara y funcionara sin tales desigualdades-, aquellas afirmaciones acerca de la libertad y la igualdad legal de los indios respecto del resto de los ciudadanos, fueron confirmadas por la Constitución de 1819, decretada por el Congreso en Tucumán bajo el nombre de "Constitución de las Provincias Unidas de Sud América". En la misma, se reafirmó el derecho a la igualdad ante la ley y además, se sancionaron nuevos principios en la legislación argentina. Entre estos últimos, se encontraba la norma según la cual los indios eran considerados iguales en dignidad y derechos a los demás ciudadanos, estableciéndose que debían ser regidos por las mismas leyes ${ }^{54}$.

De esta manera, quedaba sin efecto la norma de la antigua legislación colonial

\footnotetext{
${ }^{53}$ Barreneche, O. (2001). Op. cit., p. 66-72.

54 Estatutos, reglamentos y constituciones argentinas (1811-1898). Facultad de Filosofía y Letras, Instituto de Historia Argentina Dr. Emilio Ravignani. Capítulo II, Derechos particulares, CXXVIII.
} 
según la cual se instituía una judicatura especial para los pueblos de indios, diferente y más simple que la que regía para el resto de la población. Tal derogación se llevó efectivamente a la práctica porque no se organizó una magistratura para los indios diferente de la existente para juzgar a los demás habitantes del país y con ello, se plasmó el reconocimiento de los indios como ciudadanos en la legislación ${ }^{55}$. Pero en la praxis ¿el indígena fue tratado realmente como un sujeto de derechos? y en consecuencia ¿gozó de igualdad ante la ley? Podríamos pensar que sí tomando en cuenta el asunto analizado: la construcción del presente caso criminal, el juzgamiento y la condena, todo efectuado acorde al régimen jurídico-legal de Buenos Aires (y con independencia absoluta del sistema judicial indígena), y finalmente lo actuado y alegado por parte del Agente Fiscal y el Juez de Primera Instancia (quién tuvo a cargo la evaluación final del caso y la sentencia), son los elementos en base a los cuales podemos pensar que el indio Francisco "Pampa" Economi, en calidad de imputado, efectivamente fue un "titular" del derecho a la igualdad jurídica. Cabe desatacar que para el indio, la igualdad ante la ley no necesariamente significó igualdad social en la práctica, ya que nunca recibió igual trato social y se encontraba inmerso en el contexto de una sociedad aún altamente jerarquizada ocupando uno de los estratos más bajos de la misma: poseer igualdad jurídica no era equivalente a gozar del derecho a la igualdad social.

\section{VI- Consideraciones finales}

El documento judicial analizado permitió observar el desarrollo de la causa completa, a través de las distintas instancias del proceso, como así también a los diversos actores participando activamente del mismo. Comenzando por los magistrados superiores, el Agente Fiscal y el Juez (quién siempre avaló la postura del primero) se abocaron a la búsqueda de evidencias concretas y que no dejaran duda alguna de la responsabilidad directa del reo en el crimen, a fin de obtener una culpabilidad certera y verificada. De este modo, contaron con pruebas materiales y testimoniales precisas, en conformidad con las cuales se dictó la sentencia.

Por su parte, la voz del imputado fue relevada en el proceso pero sus alegatos no tuvieron peso frente a la de los distintos testigos, varios de ellos también indios.

\footnotetext{
55 Silvia Ratto ha alegado que dicha noción de hermandad con los indios por parte del gobierno, se relacionaba con una política indígena de tendencia filo-indigenista por parte del gobierno, que buscaba superar la relación monarca-súbdito propia del período colonial, para integrar al indio dentro del Estado como hermano y compatriota. Pero para Tulio Halperín Donghi (2005) la postura del gobierno, más que una convicción respondía a la mera necesidad de obtener partidarios en un contexto de escasa adhesión a la causa. Ratto, S. (2003). Op. cit.
} 
Asimismo, estos funcionarios consideraron a Economi como un habitante del Estado y dictaminaron que, en tanto viviera en territorio de la provincia, debía ser juzgado acorde al régimen jurídico de Buenos Aires y sin aplicarse procedimientos o normativas indígenas. Desde la perspectiva del Juez y del Fiscal existía una sanción jurídica contra este indio, la cual era percibida como legítima para la institución judicial. De acuerdo a esto, es posible pensar que Economi gozó del derecho de igualdad ante la ley y sin que influya o condicione la diferenciación étnica (en una sociedad aún fuertemente estamental) pese a que el Protector -con el mero propósito de obtener la absolución de su representadocentró parte de la defensa en la "barbarie" y demás rasgos de interiorización, que se suponían propios del indio; sin duda, su postura respondía a un pensamiento etnocéntrico vigente desde los tiempos de la Conquista.

En realidad, lejos estuvieron las argumentaciones del abogado defensor, de asemejarse a los principios de justicia e "igualdad" percibidos en las actuaciones y discursos de los otros magistrados. Lo cierto es que la oposición entre sus posturas pudo haber respondido a la misma inestabilidad jurídica existente en ese momento. Tal como afirma Osvaldo Barreneche, la revolución de 1810 creó condiciones políticas para la continuidad del marco legal colonial y si bien se incorporaron diversas modificaciones en la legislación vigente, no se abolieron las leyes coloniales en su totalidad. Así, la administración de la justicia criminal en Buenos Aires, durante el período de 1810 a 1853 (año en que se estableció la Constitución Nacional) debió adaptar normativas y prácticas de la Colonia en un contexto de experimentación institucional donde convivían aplicaciones de nuevos procedimientos junto a prácticas coloniales aún vigentes. En este sentido, los delitos sexuales, homicidios, robos, etc. podían ser juzgados acorde al código penal colonial, es decir, a la luz de lo que la Séptima Partida podía sentenciar sobre ellos, pero al mismo tiempo, podía observarse la emergencia de tipos penales más abstractos que posteriormente constituyeron aspectos de los códigos penales modernos.

No obstante esta realidad existente en la justicia criminal de Buenos Aires, existió un punto en el cual los juristas coincidieron relativamente con el abogado defensor de Economi: el argumento de la ebriedad. Según consta en el expediente, la pena de cinco años de prisión (y otros agregados) originalmente solicitada por el Fiscal, se aplicaba por homicidio y ebriedad; pero en la resolución final, quedó reducida a sólo dos años de encierro, siendo éste el único cambio efectuado en la sentencia del Fiscal. Si bien en el expediente no se aclaró el motivo de la modificación, es nuestra tesis que el estado alcoholizado, actuó como atenuante de la pena dictaminada desde el inicio del proceso, 
por motivos ya expresados en los apartados previos. Sin embargo, los demás alegatos de la defensa no pudieron lograr el sobreseimiento, es decir, no revirtieron la situación jurídica del indígena en su calidad de procesado, imputado y finalmente condenado conforme al Derecho que regía en Buenos Aires.

\section{Referencias}

Barabas, Alicia (2000). "La construcción del indio como bárbaro: de la etnografía al indigenismo". In Alteridades v. 10, n. 19, p. 9-20.

Barreneche, Osvaldo. (2001). Dentro de la ley, Todo. La justicia criminal de Buenos Aires en la etapa formativa del sistema penal moderno de la Argentina, La Plata: Al Margen.

Bonfil Batalla, Guillermo (1972). "El concepto de indio en América. Una categoría de la situación colonial”. In Anales de Antropología, v. 9, p.105-124.

Davilo, Beatriz. (2011). Los derechos, las pasiones, la utilidad. Debate intelectual y lenguajes políticos en Buenos Aires (1810-1827), Buenos Aires: EDUNTREF.

Farberman, J.; Ratto, S. (Coord.) (2009). Historias mestizas en el Tucumán colonial y las pampas (siglos XVIII-XIX), Buenos Aires: Biblos.

Gallegos Vázquez, Rafael (2003). Los conceptos "indio" y "ladino": construcciones histórico sociales definidas por sus relaciones. Disponible en:

http://www.url.edu.gt/PortalURL/Archivos/83/Archivos/Departamento\%20de\%20Investigaci ones\%20y\%20publicaciones/Articulos\%20Doctrinarios/Pol\%C3\%ADticas/Conceptos\%20d e\%20indio\%20y\%20ladino.pdf. Consulta: el 19 de diciembre de 2011.

Gayol, Sandra y Kessler, Gabriel (Comp.) (2002). Violencias, delitos y justicias en la Argentina, Buenos Aires: Ediciones Manantial.

Mandrini, Raúl (1992). "Indios y fronteras en el área pampeana (siglos XVI-XIX). Balance y perspectiva". In Anuario IEHS, n. 7. p. 59-73.

(2008). La Argentina aborigen. De los primeros pobladores a 1910, Buenos Aires: Siglo XXI Editores.

Quijada, Mónica (2001). “Indígenas: violencia, tierras y ciudadanía”. In Quijada, M.; Bernand, C.; Schneider, A. (2001). Homogeneidad y Nación con un estudio de caso: Argentina, siglos $X I X$ y $X X$, Madrid: Consejo Superior de Investigaciones Científicas. Centro de Humanidades. Instituto de Historia, p. 57-92.

(2002). Repensando la frontera sur argentina: concepto, contenido, continidades y discontinuidades de una realidad espacial y étnica (siglos XVIII-XIX). Disponible en: http://digital.csic.es/bitstream/10261/8769/1/REPENSANDO\%20LA\%20FRONTERA\%20S UR\%20ARGENTINA.pdf. Consulta: el 1de abril de 2012 
Ratto, Silvia (2003). “¿Soberanos, "clientes” o vecinos?: algunas consideraciones sobre la condición de los indígenas en la sociedad bonaerense". In Villar, D.; Jiménez, F. y Ratto, S. (Ed.) (2003). Conflicto, poder y justicia en la frontera bonaerense, 1818-1832, Bahía Blanca y Santa Rosa: Universidad Nacional del Sur y Universidad Nacional de La Pampa, p. 145-164.

(2005). Caciques, autoridades fronterizas y lenguaraces: intermediarios culturales e interlocutores válidos en Buenos Aires (primera mitad del siglo XIX). Disponible en: http://www.scielo.org.ar/scielo.php?script=sci_arttext\&pid=S1515-59942005000100008, consulta: el 7 de mayo de 2008.

Revilla Blanco, M. (2005). "Propuesta para un análisis del movimiento indígena como movimiento social". In Política y Sociedad, v. 42, n. 2, p. 49-62.

Salvatore, Ricardo; Aguirre, Carlos (2001). "Introduction". In Salvatore, Ricardo; Aguirre, Carlos; Joseph, Gilbert M. (Orgs) (2001). Crime and punishment in Latin America. Law and society since late colonial times, London: Duke University Press, p. 1-25.

Taylor, William (1987). Embriaguez, homicidio y rebelión en las poblaciones coloniales mexicanas, México: Fondo de Cultura Económica.

\section{Fuentes Documentales}

Archivo Histórico de la Provincia de Buenos Aires "Dr. Ricardo Levene". La Plata. Sección Juzgado del Crimen. 1810:4-2-33-6;1810:34-2-33-24;1812:34-2-34-20;1812:34-2-3476;1814:34-2-35-75;1818:34-2-37-1;1818:34-2-37-2;1818:34-2-37-22;1818:34-2-37-

52;1818:34-2-37-56;1821:34-2-41-3;1822:34-2-43-24;1824:34-3-53-114;1825:34-3-58-

8;1825:34-3-61-9; 1825: 34-3-62-7;1826: 34-4-68-106;1827: 34-4-74-69; 1828: 34-4-81$32 ; 1834: 41-1-111$.

Archivo Histórico de la Provincia de Buenos Aires "Dr. Ricardo Levene". La Plata. Sección Juzgado del Crimen. "Criminal contra el Indio Pampa F.Economi, por haver asesinado al de la misma clase Queuna”. 1823: 34-3-48-13.

Estatutos, reglamentos y constituciones argentinas (1811-1898). Facultad de Filosofía y Letras, Instituto de Historia Argentina Dr. Emilio Ravignani. Capítulo II, Derechos particulares, CXXVIII.

Recebido para publicação em novembro de 2011.

Aprovado para publicação em julho de 2012. 